\title{
Improvement of skeletal muscle insulin sensitivity by 1 week of SGLT2 inhibitor use
}

\author{
Yuka Goto', Yoshie Otsuka', Kenji Ashida(1) ', Ayako Nagayama', Nao Hasuzawa', Shimpei Iwata', Kento Hara', \\ Munehisa Tsuruta', Nobuhiko Wada', Seiichi Motomura ${ }^{1,2}$, Yuji Tajiri ${ }^{1,2}$ and Masatoshi Nomura ${ }^{1}$ \\ 'Division of Endocrinology and Metabolism, Department of Internal Medicine, Kurume University School of Medicine, Asahi-machi, Kurume-city, \\ Fukuoka, Japan \\ ${ }^{2}$ Division of Endocrinology and Metabolism, Diabetes Center, Kurume Medical Center, Kokubu-machi, Kurume-city, Fukuoka, Japan
}

Correspondence should be addressed to K Ashida: ashida@med.kurume-u.ac.jp

\begin{abstract}
Background and Aims: It is currently unclear whether sodium-glucose co-transporter 2 (SGLT2) inhibitor administration can improve the insulin sensitivity as well as rapidly reduce plasma glucose concentrations in humans during the early phase of treatment initiation. This study aimed to investigate the effect of SGLT2 inhibitor on insulin sensitivity in the early phase of treatment initiation.

Methods and Results: This single-center, open label, and single-arm prospective study recruited 20 patients (14 men) with type 2 diabetes mellitus (T2DM). We examined the patients' metabolic parameters before and 1 week after SGLT2 inhibitor (10 mg/day of empagliflozin) administration. The glucose infusion rate (GIR) was evaluated using the euglycemic hyperinsulinemic glucose clamp technique. Changes in laboratory and anthropometric parameters before and after SGLT2 inhibitor administration were analyzed according to the change in the GIR. The BMI, body fat amount, skeletal muscle amount, systolic blood pressure, and triglyceride level significantly decreased along with the treatment, while urinary glucose level and log GIR value significantly increased. Notably, changes in the GIR after SGLT2 inhibitor administration, which indicated improvement in peripheral insulin sensitivity, were negatively correlated with T2DM duration and positively with reduction in fluctuation of daily plasma glucose profiles before and after treatment.

Conclusion: SGLT2 inhibitor improved insulin sensitivity in the skeletal muscle independent of anthropometric changes. Patients with short duration of T2DM and insulin resistance can be good candidates for short-term SGLT2 inhibitor administration to improve insulin sensitivity in the skeletal muscle.
\end{abstract}

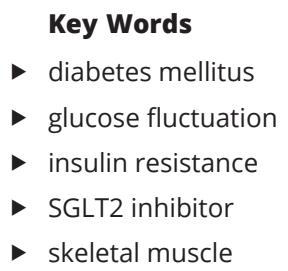

\section{Introduction}

Sodium-glucose co-transporter 2 (SGLT2) inhibitors exert plasma glucose-lowering effects via urinary glucose excretion. Recent clinical trials have shown the various beneficial effects of SGLT2 inhibitors, including reductions in the risk of cardiovascular events and mortality in diabetes mellitus $(1,2)$. SGLT2 inhibitors exert glucose-lowering effects, improving insulin sensitivity through the changes in the body composition over long-term treatment $(3,4)$.
While short-term intensive insulin therapy improves glycemic control and $\beta$-cell function (5), rapid ameliorations of insulin sensitivity in response to plasma glucose normalization have been controversially discussed $(6,7)$. In addition, insulin resistance is a major risk factor for the development of macrovascular complications in patients with type 2 diabetes mellitus (T2DM) $(8,9)$. Thus, glucose regulation therapy for the improvement of

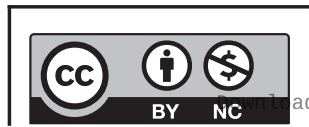

This work is licensed under a Creative Commons Attribution-NonCommercial 4.0 International License. ded from Bioscientifica.com at 04/26/2023 09:32:21AM 
insulin sensitivity, the avoidance of obesity, and the inhibition of hypoglycemia are required to prevent macrovascular complications $(1,10,11)$.

In an animal model, SGLT2 inhibitors exerted amelioration effects against insulin resistance by reducing ectopic fat volume $(12,13)$ and increasing the glucose consumption rate (12) in the muscle. However, it remained unclear whether SGLT2 inhibitor administration can improve insulin sensitivity and rapidly reduce plasma glucose concentrations in humans during the early phase of treatment initiation.

Herein, we aimed to investigate the improvement in insulin sensitivity after short-term administration of SGLT2 inhibitor. In addition, we analyzed factors related to the amelioration of peripheral insulin sensitivity by the administration of SGLT2 inhibitor.

\section{Materials and methods}

\section{Study population}

This prospective, single-center, and single-arm clinical study evaluated 269 patients with T2DM who were admitted to the Kurume University Hospital between July 1, 2017 and December 31, 2018. Patients aged over 20 years with glycated hemoglobin (HbA1c) levels higher than 8.0\%/63 mmol/mol (National Glycohemoglobin Standardization Program) (International Federation of Clinical Chemistry and Laboratory Medicine) and preserved insulin secretion (fasting serum C-peptide $\geq 0.6 \mathrm{ng} / \mathrm{mL}$ ) (14) were included. After excluding 249 patients due to the change of medication for the treatment of diabetes during the evaluation period $(n=117)$, use of s.c. insulin injection $(n=106)$, severe liver and/or renal dysfunction $(n=14)$, and refusal to participate ( $n=12), 20$ patients ( 14 men and 6 women) were finally included.

All procedures were performed in accordance with the ethical standards of the Institutional Review Board of Kurume University School of Medicine and the principles of the Declaration of Helsinki 2013. Written informed consent was obtained from all participants. This study was approved by the Ethics Committee of Kurume University School of Medicine (approval number 17147).

\section{Experimental protocol}

Empagliflozin, an SGLT2 inhibitor, was orally administered at a dose of $10 \mathrm{mg} /$ day for 1 week. Metabolic and anthropometric data were collected before and 1 week after the initiation of empagliflozin. Metabolic parameters included plasma glucose concentration, HbA1c, low- and high-density lipoprotein (LDL and HDL) cholesterol, triglyceride, alanine aminotransferase (ALT), aspartate aminotransferase (AST), and uric acid levels, which were measured according to the standard procedures in the early morning after an 8-h fast. The urinary glucose levels were examined along with the urinary volume of the day and calculated as the excreted amount per day. The amounts of skeletal muscle and body fat and their distributions were analyzed before and 1 week after the administration of empagliflozin through a body composition analyzer (InBody 720, Tokyo, Japan) using the bio-impedance method.

In addition, we investigated the glucose infusion rate (GIR) before and 1 week after the administration of empagliflozin using the euglycemic hyperinsulinemic glucose clamp technique with the STG-55 artificial pancreas model (Nikkiso, Tokyo, Japan), as previously described $(15,16)$. In brief, regular insulin (Humalin R; Eli Lilly \& Co.) was loaded during the first $10 \mathrm{~min}$ of the clamp in priming doses followed by continuous infusion at a rate of $1.25 \mathrm{mU} / \mathrm{kg} / \mathrm{min}$. Blood glucose levels were determined every 5 min during the 120-min clamp study, and a euglycemic state $(5.6 \mathrm{mmol} / \mathrm{L})$ was maintained through the infusion of variable amounts of $10 \%$ glucose solution, as determined by the built-in computer program according to the control algorithm. The peripheral glucose disposal rate was evaluated as the mean of the GIR ( $\mathrm{mg} / \mathrm{kg} / \mathrm{min}$ ) during the last $30 \mathrm{~min}$ of the clamp study. Empagliflozin administration was terminated 1 day before (over $24 \mathrm{~h}$ ) the second GIR measurement. Because the urinary excretion rate is low enough after $24 \mathrm{~h}$ from the last administration (17), GIR values were not collected with subtraction of urinary glucose levels as in a previous study on dapagliflozin (7).

In another series of experiments, endogenous insulin secretion was evaluated before and after 1-week treatment with empagliflozin. Serum C-peptide levels were measured before and 1-2 h after breakfast, at which one-third of total daily calorie intake (carbohydrates $60 \%$ ) was consumed. Additionally, daily plasma glucose profiles were examined before and after empagliflozin administration.

\section{Statistical analysis}

Data were presented as mean \pm s.D. Because GIR values were not normally distributed on evaluation by ShapiroWilk test, they were converted into their natural

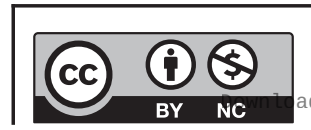

This work is licensed under a Creative Commons Attribution-NonCommercial 4.0 International License. ded from Bioscientifica.com at 04/26/2023 09:32:21AM 
logarithmic values. We used the log GIR value instead of the GIR value itself for further analysis. Changes in the laboratory parameters before and after the administration of empagliflozin were expressed as $\Delta$ values (the value after administration minus that before administration). Correlations of $\log$ GIR or $\Delta$ GIR as an outcome variable with other parameters as predictive variables were analyzed using Pearson's correlation coefficient. Changes in metabolic and anthropometric parameters related to 1-week empagliflozin administration were analyzed using paired $t$-test. All statistical analyses were performed using $\mathrm{JMP}^{\circledR} 13$ (SAS Institute Inc., Cary, NC, USA). $P$-values less than 0.05 were defined as statistically significant.

\section{Results}

\section{Baseline participant characteristics}

The baseline characteristics of the 20 participants are shown in Table 1 . The average age was $54.9 \pm 15.3$ years, and $8(40 \%)$ patients were aged over 65 years. The average BMI $\left(\mathrm{kg} / \mathrm{m}^{2}\right)$ was $26.6 \pm 4.2$, and 11 patients $(55 \%)$ were diagnosed with higher than class I obesity according to Japanese criteria (18). Hypertension ( $>140 \mathrm{mmHg}$ of systolic or $90 \mathrm{mmHg}$ of diastolic blood pressure) or anti-hypertension drug use was observed in 9 (45\%) participants. With respect to liver function, 15 (75\%) and $6(30 \%)$ patients showed higher levels of ALT (over 30 IU/L) and AST (over $30 \mathrm{IU} / \mathrm{L}$ ), respectively. Dyslipidemia ( $>3.51 \mathrm{mmol} / \mathrm{L}$ of LDL-cholesterol or $1.69 \mathrm{mmol} / \mathrm{L}$ of triglyceride, or $<1.68 \mathrm{mmol} / \mathrm{L}$ of HDL-cholesterol) or the use of anti-dyslipidemia drug was observed in six (30\%) participants. The average GIR was $3.71 \pm 1.58 \mathrm{mg} / \mathrm{kg} / \mathrm{min}$, which was lower than the reference range (19), indicating the existence of insulin resistance in this group of patients (Table 1). The log GIR showed significant negative correlations with the Homeostatic Model Assessment of Insulin Resistance (HOMA-IR), an index of insulin resistance, and transaminase levels before the administration of empagliflozin (Table 2), while non-logtransformed GIR values showed similar significant results. Other variables, including age, body composition, glucose metabolism, serum uric acid and lipid metabolism, and urinary glucose excretion, did not show any significant correlations with the log GIR (Table 2).

\section{Changes in metabolic and anthropometric parameters according to empagliflozin administration}

The values of BMI, body fat mass, and skeletal muscle mass significantly decreased along with the administration of empagliflozin for 1 week (Table 3 ). The systolic blood pressure and serum triglyceride levels decreased significantly during the 1-week treatment period, although the diastolic blood pressure, HDLcholesterol, LDL-cholesterol values, and s.D. values in the plasma glucose profiles did not change (Table 3). Furthermore, the amount of urinary glucose excretion and log GIR significantly increased after the administration of empagliflozin for 1 week (Table 3).

Table 1 Baseline participant characteristics $(n=20)$.

\begin{tabular}{l}
\hline Variables \\
\hline Sex \\
Age, years \\
BMI, kg/m² \\
Systolic blood pressure, $\mathrm{mmHg}$ \\
Diastolic blood pressure, $\mathrm{mmHg}$ \\
Fasting plasma glucose concentration, $\mathrm{mmol} / \mathrm{L}$ \\
HbA1c, NGSP $(\%)$ (IFCC (mmol/mol)) \\
Fasting serum C-peptide, $\mathrm{ng} / \mathrm{mL}$ \\
Glucose infusion rate, $\mathrm{mg} / \mathrm{kg} / \mathrm{min}$ \\
Aspartate aminotransferase, IU/L \\
Alanine aminotransferase, IU/L \\
Uric acid, $\mu$ mol/L \\
HDL-cholesterol, mmol/L \\
Triglyceride, mmol/L \\
LDL-cholesterol, $\mathrm{mmol} / \mathrm{L}$ \\
\hline
\end{tabular}

\begin{tabular}{c} 
Value \\
\hline Male $(14)$, Female $(6)$ \\
$54.9 \pm 15.3$ \\
$26.6 \pm 4.2$ \\
$126.0 \pm 15.0$ \\
$77.7 \pm 11.1$ \\
$10.4 \pm 2.6$ \\
$11.1 \pm 2.9(98.2 \pm 15.8)$ \\
$2.36 \pm 1.21$ \\
$3.71 \pm 1.58$ \\
$29.6 \pm 19.7$ \\
$37.5 \pm 33.4$ \\
$343 \pm 101$ \\
$1.17 \pm 0.25$ \\
$1.73 \pm 0.76$ \\
$3.19 \pm 0.90$
\end{tabular}

\begin{tabular}{c}
\hline Reference range \\
\hline NA \\
NA \\
$18.5-24.9$ \\
$<140$ \\
$<90$ \\
$<7.0$ \\
$<6.0(<42.1)$ \\
$0.61-2.09$ \\
$9.13 \pm 4.75$ \\
$13-30$ \\
$10-30$ \\
$220-416$ \\
$>1.03$ \\
$<1.68$ \\
$<3.59$
\end{tabular}

Values are presented as means \pm S.D.

HbA1C, glycated hemoglobin; HDL, high-density lipoprotein; IFCC, International Federation of Clinical Chemistry and Laboratory Medicine; LDL, lowdensity lipoprotein; NGSP, National Glycohemoglobin Standardization Program.

https://ec.bioscientifica.com

https://doi.org/10.1530/EC-20-0082 (c) 2020 The authors Published by Bioscientifica Ltd

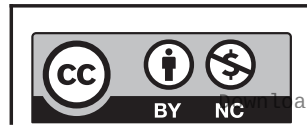

This work is licensed under a Creative Commons Attribution-NonCommercial 4.0 International License. ded from Bioscientifica.com at 04/26/2023 09:32:21AM via free access 
Table 2 Correlations between log-transformed glucose infusion rate and metabolic or anthropometric parameters.

Variables

Age, years

$\mathrm{BMl}, \mathrm{kg} / \mathrm{m}^{2}$

Skeletal muscle mass, $\mathrm{kg}$

Fat mass, $\mathrm{kg}$

HbA1c (NGSP, \%; IFCC, mmol/mol)

Fasting plasma glucose concentration, $\mathrm{mmol} / \mathrm{L}$

HOMA-IR value

Urinary glucose excretion, g/day

Aspartate transaminase, IU/L

Alanine transaminase, IU/L

Serum uric acid, $\mu \mathrm{mol} / \mathrm{L}$

$\mathrm{HDL}$-cholesterol, $\mathrm{mmol} / \mathrm{L}$

Triglyceride, $\mathrm{mmol} / \mathrm{L}$

LDL-cholesterol, $\mathrm{mmol} / \mathrm{L}$

\begin{tabular}{|c|c|}
\hline \multicolumn{2}{|c|}{ Log-transformed glucose infusion rate } \\
\hline$R$ & $P$-value \\
\hline 0.38 & 0.10 \\
\hline-0.35 & 0.13 \\
\hline-0.42 & 0.066 \\
\hline-0.01 & 0.97 \\
\hline-0.10 & 0.67 \\
\hline-0.22 & 0.36 \\
\hline-0.59 & $0.0063^{\mathrm{a}}$ \\
\hline-0.06 & 0.79 \\
\hline-0.52 & $0.019^{a}$ \\
\hline-0.64 & $0.0025^{\mathrm{a}}$ \\
\hline 0.05 & 0.84 \\
\hline 0.16 & 0.50 \\
\hline-0.02 & 0.93 \\
\hline-0.23 & 0.33 \\
\hline
\end{tabular}

Statistical significance was determined via Pearson's correlation coefficient. Values in bold ${ }^{\text {a }}$ indicate $P<0.05$

HbA1c, glycated hemoglobin; HDL, high-density lipoprotein; HOMA-IR, Homeostatic Model Assessment of Insulin Resistance; IFCC, International

Federation of Clinical Chemistry and Laboratory Medicine; LDL, low-density lipoprotein; NGSP, National Glycohemoglobin Standardization Program.

Additionally, SGLT2 inhibitor administration improved the GIR value significantly in the obese group (BMI $\geq 25 \mathrm{~kg} / \mathrm{m}^{2}$ ). Non-obese group (BMI $<25 \mathrm{~kg} / \mathrm{m}^{2}$ ) showed high GIR value before SGLT2 inhibitor administration and the tendency to further increase following SGLT2 inhibitor administration.

\section{Factors associated with the improvement of peripheral insulin sensitivity}

The changes in the log GIR ( $\Delta \log$ GIR) before and after the administration of empagliflozin showed a significant negative correlation with the change in the s.D. in the

Table 3 Changes in metabolic and anthropometric parameters by the administration of empagliflozin.

\begin{tabular}{l} 
Variables \\
\hline BMI, $\mathrm{kg} / \mathrm{m}^{2}$ \\
Body weight, $\mathrm{kg}$ \\
$\mathrm{BMI} \geq 25 \mathrm{~kg} / \mathrm{m}^{2}(n=11)$ \\
$\mathrm{BMI}<25 \mathrm{~kg} / \mathrm{m}^{2}(n=9)$ \\
Body fat mass, $\mathrm{kg}$ \\
Body skeletal muscle mass, $\mathrm{kg}$ \\
Systolic blood pressure, $\mathrm{mmHg}$ \\
Diastolic blood pressure, $\mathrm{mmHg}$ \\
FPG, mmol/L \\
BMI $\geq 25 \mathrm{~kg} / \mathrm{m}^{2}(n=11)$ \\
BMI $<25 \mathrm{~kg} / \mathrm{m}^{2}(n=9)$ \\
Aspartate transaminase, IU/L \\
Alanine transaminase, IU/L \\
Uric acid, $\mu \mathrm{mol} / \mathrm{L}$ \\
HDL-cholesterol, mmol/L \\
Triglyceride, mmol/L \\
LDL-cholesterol, mmol/L \\
Urinary glucose excretion, g/day \\
Glucose infusion rate, mg/kg/min \\
log (glucose infusion rate) $(n=20)$ \\
BMI $\geq 25 \mathrm{~kg} / \mathrm{m}^{2}(n=11)$ \\
BMI $<25 \mathrm{~kg} / \mathrm{m}^{2}(n=9)$ \\
S.D. value in plasma glucose profiles
\end{tabular}

\begin{tabular}{c} 
Before \\
\hline $26.6 \pm 4.17$ \\
$73.0 \pm 15.3$ \\
$83.6 \pm 10.8$ \\
$60.0 \pm 7.9$ \\
$24.1 \pm 8.24$ \\
$27.0 \pm 5.97$ \\
$126 \pm 29.7$ \\
$77.7 \pm 21.8$ \\
$10.4 \pm 2.64$ \\
$10.8 \pm 2.64$ \\
$9.98 \pm 2.73$ \\
$39.6 \pm 38.9$ \\
$37.5 \pm 66.1$ \\
$343 \pm 101$ \\
$1.17 \pm 0.25$ \\
$1.73 \pm 0.76$ \\
$3.19 \pm 0.90$ \\
$24.5 \pm 35.1$ \\
$3.71 \pm 1.58$ \\
$0.53 \pm 0.37$ \\
$0.46 \pm 0.17$ \\
$0.62 \pm 0.17$ \\
$2.75 \pm 0.8$
\end{tabular}

\begin{tabular}{cc}
\hline \multicolumn{1}{c}{ After } \\
\hline $25.9 \pm 4.00$ \\
$71.2 \pm 14.8$ \\
$81.4 \pm 10.6$ \\
$58.8 \pm 7.9$ \\
$23.1 \pm 7.44$ \\
$26.5 \pm 6.32$ \\
$116 \pm 27.5$ \\
$74.2 \pm 24.6$ \\
$6.62 \pm 1.38$ \\
$6.75 \pm 1.14$ \\
$6.46 \pm 1.69$ \\
$27.8 \pm 19.9$ \\
$33.5 \pm 39.9$ \\
$334 \pm 95$ \\
$1.12 \pm 0.26$ \\
$1.29 \pm 0.52$ \\
$3.05 \pm 1.11$ \\
$79.4 \pm 35.8$ \\
$4.80 \pm 1.52$ \\
$0.66 \pm 0.27$ \\
$0.63 \pm 0.10$ \\
$0.69 \pm 0.18$ \\
$2.46 \pm 0.9$
\end{tabular}

\begin{tabular}{|c|}
\hline P-value \\
\hline$<0.001^{a}$ \\
\hline$<0.001^{a}$ \\
\hline$<0.001^{a}$ \\
\hline$<0.001^{a}$ \\
\hline $0.0072^{a}$ \\
\hline $0.0082^{a}$ \\
\hline $0.0078^{a}$ \\
\hline 0.14 \\
\hline$<0.001^{a}$ \\
\hline $0.0010^{a}$ \\
\hline $0.0039^{a}$ \\
\hline 0.56 \\
\hline 0.4 \\
\hline 0.59 \\
\hline 0.65 \\
\hline$<0.001^{a}$ \\
\hline 0.2 \\
\hline$<0.001^{a}$ \\
\hline $0.0036^{a}$ \\
\hline $0.0031^{a}$ \\
\hline $0.011^{a}$ \\
\hline 0.15 \\
\hline 0.20 \\
\hline
\end{tabular}

Values are presented as means \pm S.D.

Analysis using paired $t$-test. Values in bold a indicate $P<0.05$.

FPG, fasting plasma glucose; HDL, high-density lipoprotein; LDL, low-density lipoprotein.

https://ec.bioscientifica.com

https://doi.org/10.1530/EC-20-0082 (c) 2020 The authors Published by Bioscientifica Ltd

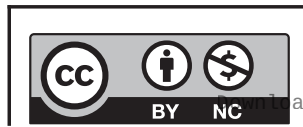

This work is licensed under a Creative Commons Attribution-NonCommercial 4.0 International License. ded from Bioscientifica.com at 04/26/2023 09:32:21AM 
Table 4 Correlations between $\Delta \log$ glucose infusion rate and changes in metabolic or anthropometric parameters by the administration of empagliflozin.

Variables

$\Delta$ Urinary glucose excretion, g/day

$\Delta$ Fasting plasma glucose concentration, $\mathrm{mmol} / \mathrm{L}$ $\Delta$ Mean plasma glucose concentration, $\mathrm{mmol} / \mathrm{L}$ $\Delta$ s.D. value in plasma glucose profiles $\Delta$ Fasting serum C-peptide, $\mathrm{ng} / \mathrm{mL}$ $\Delta$ Fasting serum $\mathrm{C}$-peptide index $\triangle \mathrm{BMI}, \mathrm{kg} / \mathrm{m}^{2}$

$\Delta$ Body fat mass, $\mathrm{kg}$

$\triangle$ Skeletal muscle mass, $\mathrm{kg}$

$\triangle$ Aspartate transaminase, IU/L

$\Delta$ Alanine transaminase, IU/L

$\Delta$ Serum uric acid, $\mu \mathrm{mol} / \mathrm{L}$

\begin{tabular}{cll}
\hline \multicolumn{3}{c}{$\Delta \operatorname{llog}$ glucose infusion rate } \\
\hline \multicolumn{1}{c}{$r$} & & $P$-value \\
\hline 0.19 & 0.46 \\
0.022 & 0.93 \\
-0.051 & 0.84 \\
-0.55 & $\mathbf{0 . 0 1 6}$ \\
-0.32 & 0.18 \\
-0.10 & 0.67 \\
-0.43 & 0.056 \\
-0.092 & 0.71 \\
-0.082 & 0.74 \\
-0.40 & 0.066 \\
-0.39 & 0.092 \\
-0.40 & 0.080
\end{tabular}

Serum C-peptide indexes were calculated as serum C-peptide levels divided by plasma glucose levels. Values were assessed via Pearson's correlation coefficient. Values in bold a indicate $P<0.05$

plasma glucose profiles (Table 4). However, the $\Delta$ log GIR did not show any significant correlations with changes in the anthropometric values, including those of BMI, body fat mass, and skeletal mass, while the mean levels of these parameters in all participants significantly decreased (Table 3). Additionally, the $\Delta \log$ GIR did not show any significant correlations with changes in transaminase and serum uric acid (Table 4). Additionally, the $\Delta \log$ GIR showed a significant negative correlation with the duration of T2DM and significant positive correlations with body fat mass, HOMA-IR, and transaminase levels before the administration of empagliflozin (Table 5). With regard to the stratified analysis, $\Delta \log$ GIR negatively correlated with diabetes mellitus duration only in the obese group (BMI $\geq 25 \mathrm{~kg} / \mathrm{m}^{2}$ ). In addition, $\Delta \log$ GIR correlated negatively with the s.D. value of the plasma glucose profiles and positively with AST and ALT levels in the non-obese group $\left(\mathrm{BMI}<25 \mathrm{~kg} / \mathrm{m}^{2}\right)$. However, BMI and body fat mass did not show any significant correlations with $\Delta \log$ GIR in both groups. In addition, the other potential metabolic disease-related variables, including age, BMI, skeletal muscle mass, fasting plasma glucose, HbA1c, serum uric acid, and lipids, did not show significant correlations with the $\Delta \log$ GIR (Table 5). Furthermore, we found

Table 5 Correlations between $\Delta \log$ glucose infusion rate and metabolic or anthropometric parameters before the administration of empagliflozin.

\begin{tabular}{|c|c|c|c|c|c|c|}
\hline \multirow[b]{3}{*}{ Variables } & \multicolumn{6}{|c|}{$\Delta \log$ glucose infusion rate } \\
\hline & \multicolumn{2}{|c|}{ Total $(n=20)$} & \multicolumn{2}{|c|}{$\mathrm{BMI}<25 \mathrm{~kg} / \mathrm{m}^{2}(n=9)$} & \multicolumn{2}{|c|}{$\mathrm{BMI} \geq 25 \mathrm{~kg} / \mathrm{m}^{2}(n=11)$} \\
\hline & $r$ & $P$-value & $r$ & $P$-value & $r$ & $P$-value \\
\hline Age, years & -0.33 & 0.16 & 0.38 & 0.31 & -0.43 & 0.18 \\
\hline Diabetes mellitus duration, years & -0.27 & $0.031^{a}$ & 0.15 & 0.70 & -0.62 & $0.041^{a}$ \\
\hline $\mathrm{BMI}, \mathrm{kg} / \mathrm{m}^{2}$ & 0.35 & 0.13 & -0.46 & 0.22 & 0.24 & 0.48 \\
\hline Body fat mass, kg & 0.44 & $0.0495^{a}$ & 0.43 & 0.25 & 0.30 & 0.37 \\
\hline Skeletal muscle mass, kg & 0.094 & 0.69 & -0.30 & 0.43 & -0.04 & 0.91 \\
\hline HbA1c (IFCC: mmol/mol) & 0.04 & 0.88 & 0.64 & 0.066 & -0.26 & 0.44 \\
\hline Fasting PG level, mmol/L & 0.12 & 0.62 & -0.27 & 0.48 & 0.15 & 0.66 \\
\hline HOMA-IR & 0.51 & $0.023^{a}$ & 0.61 & 0.080 & 0.45 & 0.17 \\
\hline S.D. value in PG profiles & 0.011 & 0.96 & -0.71 & $0.033^{a}$ & 0.30 & 0.37 \\
\hline Urinary glucose excretion, g/day & -0.19 & 0.42 & -0.34 & 0.34 & -0.22 & 0.52 \\
\hline Aspartate transaminase, IU/L & 0.49 & $0.029^{a}$ & 0.72 & $0.030^{a}$ & 0.34 & 0.31 \\
\hline Alanine transaminase, IU/L & 0.55 & $0.013^{\mathrm{a}}$ & 0.83 & $0.0052^{a}$ & 0.47 & 0.15 \\
\hline Serum uric acid, $\mu \mathrm{mol} / \mathrm{L}$ & -0.12 & 0.62 & 0.031 & 0.94 & -0.57 & 0.070 \\
\hline HDL-cholesterol, mmol/L & -0.027 & 0.91 & 0.039 & 0.92 & 0.055 & 0.87 \\
\hline Triglyceride, mmol/L & -0.0017 & 0.99 & 0.26 & 0.50 & -0.21 & 0.52 \\
\hline LDL-cholesterol, mmol/L & -0.19 & 0.43 & 0.027 & 0.94 & 0.27 & 0.41 \\
\hline
\end{tabular}

Statistical significance determined via Pearson's correlation coefficient. Values in bold a indicate $P<0.05$.

HbA1c, glycated hemoglobin; HDL, high-density lipoprotein; HOMA-IR, Homeostatic Model Assessment of Insulin Resistance; IFCC, International Federation of Clinical Chemistry and Laboratory Medicine; LDL, low-density lipoprotein; PG, plasma glucose.

https://ec.bioscientifica.com

https://doi.org/10.1530/EC-20-0082 (c) 2020 The authors Published by Bioscientifica Ltd

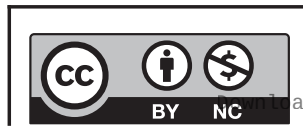

This work is licensed under a Creative Commons Attribution-NonCommercial 4.0 International License. ded from Bioscientifica.com at 04/26/2023 09:32:21AM 

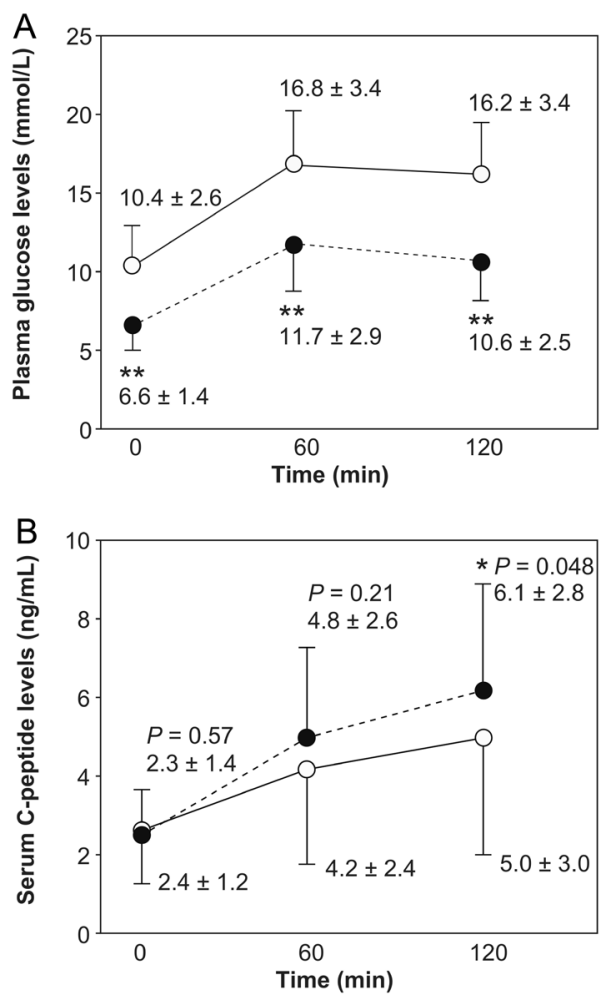

\section{Figure 1}

Improvements in insulin secretion after 1-week SGLT2 inhibitor treatment. (A) Plasma glucose and (B) serum C-peptide levels before and 60-120 min after breakfast (presented as mean \pm s.D.). Data before and after the administration of SGLT2 inhibitors are indicated as solid lines with open circles and broken lines with closed circles, respectively $(n=20)$. * and ** indicate the presence of significant differences compared to the value before SGLT2 inhibitor administration (paired $t$-test). ${ }^{*} P<0.05 . * * P<0.0001$. To convert values for glucose to millimoles per liter, multiply by 0.05551 . To convert values for insulin to picomoles per liter, multiply by 6.0. Abbreviation: SGLT2, sodium-glucose co-transporter 2 .

improvements in the levels of serum C-peptide 120 min after breakfast following the 1-week treatment with empagliflozin (Fig. 1).

\section{Discussion}

The present prospective study revealed clinically important short-term features of SGLT2 inhibitor administration. The administration of SGLT2 inhibitors can rapidly improve insulin sensitivity in the skeletal muscle within 1 week without affecting the body composition. The improvements in the rate of skeletal muscle insulin sensitivity were positively correlated with those in the rate of daily plasma glucose profile fluctuations. The duration of diabetes mellitus was not correlated with the improvement in insulin sensitivity through SGLT2 inhibitor administration. Collectively, our results suggest that the administration of SGLT2 inhibitors may be an effective strategy for the rapid amelioration of hyperglycemia, so-called glucotoxicity, particularly in the skeletal muscle.

Previously, SGLT2 inhibitor administration was shown to result in changes in body composition through the reduction of body fat mass (4). Thus, SGLT2 inhibitors improve not only hyperglycemia via the promotion of urinary glucose excretion, but also obesity via the promotion of lipolysis and prevention of lipogenesis (12). Significantly but modestly increased urinary glucose excretion occurred in our high-plasma glucose participants before empagliflozin initiation, the modest increase might be due to the hyperactivity of SGLT2 and SGLT1 in T2DM $(20,21)$. A study using 10 -week-old Zucker fatty rats with diabetes, as an early-stage human model of obese T2DM cases representing metabolic characteristics, demonstrated improvement in insulin sensitivity through the 1-week administration of SGLT2 inhibitors, with reductions in the triglyceride contents in skeletal muscles (13).

Increased intramyocellular lipid contents represent a preceding abnormality in the pathogenesis of insulin resistance and may contribute to defective glucose uptake in skeletal muscles among insulin-resistant people, independent of obesity (22). Although the pathological mechanism has not been clarified in humans, in animal models, reductions in ectopic adipose mass in skeletal muscles have been suggested to contribute to immediate improvements in insulin sensitivity by SGLT2 inhibitor administration $(12,13)$.

The improvements in skeletal muscle insulin sensitivity were positively correlated with the levels of improvement in daily plasma glucose fluctuations, but not in the fasting and mean plasma glucose levels. This finding has not been reported in any previous study, while relations between glycemic variability and glucose impairment level have been reported (23). Furthermore, improving the degree of fluctuation in the plasma glucose level through SGLT2 inhibitor administration may contribute to lowering the rate of oxidative stress, (24) which leads to further metabolic disorders and cardiovascular events $(1,24)$.

The duration of diabetes mellitus was negatively correlated with the degree of improvement in insulin sensitivity through SGLT2 inhibitor administration. Although the progressive loss of $\beta$-cell function is associated with glycemic deterioration (10), short-term intensive insulin therapy can ameliorate the disturbances in insulin sensitivity and preserve residual $\beta$-cell function in T2DM patients, particularly those with a short diabetes

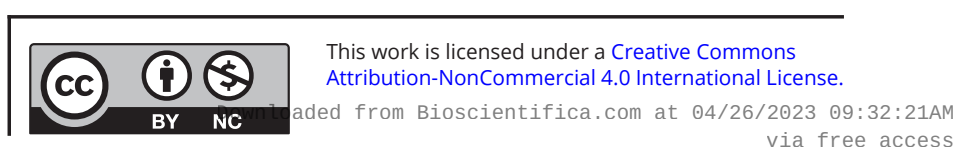


history (25). However, high-dose insulin requirements were independently associated with greater weight gain (26) when insulin therapy was initiated. Our study revealed that SGLT2 inhibitor could improve insulin sensitivity as well as insulin secretion. Thus, the oral SGLT2 inhibitor was shown to be effective in rapidly improving the glucose toxicity without body weight gain in patients with insulin resistance even with high HbA1c levels.

Considering our results and the review of the literature, SGLT2 inhibitor may improve glucose metabolism through the recovery of mitochondrial function. Disturbed cellular response to insulin in skeletal muscle is among the main risk factors for T2DM development. T2DM patients show high rates of reactive oxygen species (ROS) release from the mitochondria, resulting in low insulin-sensitivity rates $(27,28)$ and further glucose impairment (29). Disturbed mitochondrial oxidative phosphorylation (30) may lead to the dysregulation of intramyocellular fatty acid metabolism and intramyocellular lipid accumulation, which are related to insulin resistance in skeletal muscles in T2DM. SGLT2 inhibitor administration may help recover and regulate the metabolic rhythms (31) of the mitochondria.

Our study has some strength and limitations to be acknowledged. Because we enrolled the study participants from patients who were admitted to our hospital because of hyperglycemia, we were able to evaluate patients with highlevel HbA1c and those with preserved insulin secretion. Further, we used a common high-insulin infusion rate $(1.25 \mathrm{mU} / \mathrm{kg} / \mathrm{min})$ to investigate the insulin sensitivity levels in skeletal muscles $(6,19)$. However, a previous report suggested insufficient suppression of endogenous glucose production in insulin-resistant patients (32), and insufficient suppression might lead to an underestimation of GIR values. Further, while the mean HbA1c levels in the present study were high, SGLT2 inhibitor might be indicated under very careful assessment. Although we observed rapid improvements in insulin sensitivity through oral SGLT2 inhibitor administration, possibly due to the amelioration of mitochondrial dysfunction, this study could not disclose the changes in the oxidative stress markers, including ROS.

We could not evaluate the ectopic fat contents directly, although in humans, we examined these by the anthropometric method; the serum free fatty acid levels were also not examined in this study. Since the examinations of free fatty acid levels and ectopic fat contents in human subjects may give us further clues to understand the SGLT2 inhibitor benefits, future study should evaluate the ectopic fat contents and the serum fatty acid levels before and after treatment. Additionally, no placebo group was examined in this study and the body weight changes did not correlate significantly with the GIR improvement. Therefore, further examinations with larger sample sizes and a placebo group are needed to confirm the results of this study.

In conclusion, SGLT2 inhibitors can rapidly improve insulin sensitivity in the skeletal muscle within 1 week of administration without affecting body composition. The rates of improvement of insulin sensitivity in the skeletal muscle were positively correlated with those of daily plasma glucose fluctuations. The duration of diabetes mellitus was negatively correlated with the improvement in insulin sensitivity by SGLT2 inhibitor administration. Our findings indicate that SGLT2 inhibitors may be effective for reducing the degree of plasma glucose fluctuation, which correlated with the rates of glucotoxicity in skeletal muscles, particularly in patients with short T2DM duration and high HOMA-IR values and transaminase levels.

\section{Declaration of interest}

The authors declare that there is no conflict of interest that could be perceived as prejudicing the impartiality of the research reported.

\section{Funding}

This research did not receive any specific grant from any funding agency in the public, commercial or not-for-profit sector.

\section{References}

1 Zinman B, Wanner C, Lachin JM, Fitchett D, Bluhmki E, Hantel S, Mattheus M, Devins T, Johansen OE, Woerle HJ, et al. Empagliflozin, cardiovascular outcomes, and mortality in type 2 diabetes. New England Journal of Medicine 2015373 2117-2128. (https://doi. org/10.1056/NEJMoa1504720)

2 Neal B, Perkovic V, Mahaffey KW, de Zeeuw D, Fulcher G, Erondu N, Shaw W, Law G, Desai M, Matthews DR, et al. Canagliflozin and cardiovascular and renal events in type 2 diabetes. New England Journal of Medicine 2017377 644-657. (https://doi.org/10.1056/ NEJMoa1611925)

3 Bolinder J, Ljunggren Ö, Kullberg J, Johansson L, Wilding J, Langkilde AM, Sugg J \& Parikh S. Effects of dapagliflozin on body weight, total fat mass, and regional adipose tissue distribution in patients with type 2 diabetes mellitus with inadequate glycemic control on metformin. Journal of Clinical Endocrinology \& Metabolism 201297 1020-1031. (https://doi.org/10.1210/jc.2011-2260)

4 Matsuba R, Matsuba I, Shimokawa M, Nagai Y \& Tanaka Y. Tofogliflozin decreases body fat mass and improves peripheral insulin resistance. Diabetes, Obesity and Metabolism 201820 1311-1315. (https://doi.org/10.1111/dom.13211)

5 Chen HS, Wu TE, Jap TS, Hsiao LC, Lee SH \& Lin HD. Beneficial effects of insulin on glycemic control and beta-cell function in newly diagnosed type 2 diabetes with severe hyperglycemia after short-term intensive insulin therapy. Diabetes Care 200831 1927-1932. (https:// doi.org/10.2337/dc08-0075) 
6 Merovci A, Solis-Herrera C, Daniele G, Eldor R, Fiorentino TV, Tripathy D, Xiong J, Perez Z, Norton L, Abdul-Ghani MA, et al. Dapagliflozin improves muscle insulin sensitivity but enhances endogenous glucose production. Journal of Clinical Investigation 2014 124 509-514. (https://doi.org/10.1172/JCI70704)

7 Latva-Rasku A, Honka MJ, Kullberg J, Mononen N, Lehtimäki T, Saltevo J, Kirjavainen AK, Saunavaara V, Iozzo P, Johansson L, et al. The SGLT2 inhibitor dapagliflozin reduces liver fat but does not affect tissue insulin sensitivity: a randomized, double-blind, placebocontrolled study with 8-week treatment in type 2 diabetes patients. Diabetes Care 201942 931-937. (https://doi.org/10.2337/dc18-1569)

8 DeFronzo RA \& DeFronzo RA. Insulin resistance, lipotoxicity, type 2 diabetes and atherosclerosis: the missing links. The Claude Bernard lecture 2009. Diabetologia 201053 1270-1287. (https://doi. org/10.1007/s00125-010-1684-1)

9 Katakami N. Mechanism of development of atherosclerosis and cardiovascular disease in diabetes mellitus. Journal of Atherosclerosis and Thrombosis 201825 27-39. (https://doi.org/10.5551/jat.RV17014)

10 U.K. Prospective Diabetes Study Group. U.K. prospective diabetes study 16 . Overview of 6 years' therapy of type II diabetes: a progressive disease. Diabetes 199544 1249-1258. (https://doi. org/10.2337/diab.44.11.1249)

11 Action to Control Cardiovascular Risk in Diabetes Study Group, Gerstein HC, Miller ME, Byington RP, Goff DC, Bigger JT, Buse JB, Cushman WC, Genuth S, Ismail-Beigi F, et al. Effects of intensive glucose lowering in type 2 diabetes. New England Journal of Medicine 2008358 2545-2559. (https://doi.org/10.1056/NEJMoa0802743)

12 Obata A, Kubota N, Kubota T, Iwamoto M, Sato H, Sakurai Y, Takamoto I, Katsuyama H, Suzuki Y, Fukazawa M, et al. Tofogliflozin improves insulin resistance in skeletal muscle and accelerates lipolysis in adipose tissue in male mice. Endocrinology 2016157 1029-1042. (https://doi.org/10.1210/en.2015-1588)

13 O'Brien TP, Jenkins EC, Estes SK, Castaneda AV, Ueta K, Farmer TD, Puglisi AE, Swift LL, Printz RL \& Shiota M. Correcting postprandial hyperglycemia in Zucker diabetes fatty rats with an SGLT2 inhibitor restores glucose effectiveness in the liver and reduces insulin resistance in skeletal muscle. Diabetes 201766 1172-1184. (https:// doi.org/10.2337/db16-1410)

14 Jones AG \& Hattersley AT. The clinical utility of C-peptide measurement in the care of patients with diabetes. Diabetic Medicine 201330 803-817. (https://doi.org/10.1111/dme.12159)

15 DeFronzo RA, Tobin JD \& Andres R. Glucose clamp technique: a method for quantifying insulin secretion and resistance. American Journal of Physiology 1979237 E214-E223. (https://doi.org/10.1152/ ajpendo.1979.237.3.E214)

16 Yokoyama H, Emoto M, Fujiwara S, Motoyama K, Morioka T, Komatsu M, Tahara H, Koyama H, Shoji T, Inaba M, et al. Quantitative insulin sensitivity check index and the reciprocal index of homeostasis model assessment are useful indexes of insulin resistance in type 2 diabetic patients with wide range of fasting plasma glucose. Journal of Clinical Endocrinology \& Metabolism 2004 89 1481-1484. (https://doi.org/10.1210/jc.2003-031374)

17 Laffel LMB, Tamborlane WV, Yver A, Simons G, Wu J, Nock V, Hobson D, Hughan KS, Kaspers S \& Marquard J. Pharmacokinetic and pharmacodynamic profile of the sodium-glucose co-transporter-2 inhibitor empagliflozin in young people with type 2 diabetes: a randomized trial. Diabetic Medicine 201835 1096-1104. (https://doi. org/10.1111/dme.13629)

18 Examination Committee of Criteria for 'Obesity Disease' in Japan, Japan Society for the Study of Obesity. New criteria for 'obesity disease' in Japan. Japanese Circulation Journal 200266 987-992. (https://doi.org/10.1253/circj.66.987)

19 Cobb J, Gall W, Adam KP, Nakhle P, Button E, Hathorn J, Lawton K, Milburn M, Perichon R, Mitchell M, et al. A novel fasting blood test for insulin resistance and prediabetes. Journal of Diabetes Science and Technology 20137 100-110. (https://doi. org/10.1177/193229681300700112)

20 Yakovleva T, Sokolov V, Chu L, Tang W, Greasley PJ, Peilot Sjögren H, Johansson S, Peskov K, Helmlinger G, Boulton DW, et al. Comparison of the urinary glucose excretion contributions of SGLT2 and SGLT1: a quantitative systems pharmacology analysis in healthy individuals and patients with type 2 diabetes treated with SGLT2 inhibitors. Diabetes, Obesity and Metabolism 201921 2684-2693. (https://doi. org/10.1111/dom.13858)

21 Vallon V \& Thomson SC. Targeting renal glucose reabsorption to treat hyperglycaemia: the pleiotropic effects of SGLT2 inhibition. Diabetologia 201760 215-225. (https://doi.org/10.1007/s00125-016-4157-3)

22 Jacob S, Machann J, Rett K, Brechtel K, Volk A, Renn W, Maerker E, Matthaei S, Schick F, Claussen CD, et al. Association of increased intramyocellular lipid content with insulin resistance in lean nondiabetic offspring of type 2 diabetic subjects. Diabetes 199948 1113-1119. (https://doi.org/10.2337/diabetes.48.5.1113)

23 Hall H, Perelman D, Breschi A, Limcaoco P, Kellogg R, McLaughlin T \& Snyder M. Glucotypes reveal new patterns of glucose dysregulation. PLOS Biology 201816 e2005143. (https://doi. org/10.1371/journal.pbio.2005143)

24 Ceriello A. The post-prandial state and cardiovascular disease: relevance to diabetes mellitus. Diabetes/Metabolism Research and Reviews 200016 125-132. (https://doi.org/10.1002/(sici)15207560(200003/04)16:2<125::aid-dmrr90>3.0.co;2-4)

25 Wang W, Liu C, Jimenez-Gonzalez M, Song WJ \& Hussain MA. The undoing and redoing of the diabetic $\beta$-cell. Journal of Diabetes and its Complications 201731 912-917. (https://doi.org/10.1016/j. jdiacomp.2017.01.028)

26 Balkau B, Home PD, Vincent M, Marre M \& Freemantle N. Factors associated with weight gain in people with type 2 diabetes starting on insulin. Diabetes Care 201437 2108-2113. (https://doi. org/10.2337/dc13-3010)

27 Dos Santos JM, de Oliveira DS, Moreli ML \& Benite-Ribeiro SA. The role of mitochondrial DNA damage at skeletal muscle oxidative stress on the development of type 2 diabetes. Molecular and Cellular Biochemistry 2018449 251-255. (https://doi.org/10.1007/s11010018-3361-5)

28 Hey-Mogensen M, Højlund K, Vind BF, Wang L, Dela F, Beck-Nielsen H, Fernström M \& Sahlin K. Effect of physical training on mitochondrial respiration and reactive oxygen species release in skeletal muscle in patients with obesity and type 2 diabetes. Diabetologia 201053 1976-1985. (https://doi.org/10.1007/s00125-010-1813-x)

29 Schrauwen P, Schrauwen-Hinderling V, Hoeks J \& Hesselink MK. Mitochondrial dysfunction and lipotoxicity. Biochimica et Biophysica Acta 20101801 266-271. (https://doi.org/10.1016/j.bbalip.2009.09.011)

30 Petersen KF, Dufour S, Befroy D, Garcia R \& Shulman GI. Impaired mitochondrial activity in the insulin-resistant offspring of patients with type 2 diabetes. New England Journal of Medicine 2004350 664-671. (https://doi.org/10.1056/NEJMoa031314)

31 Esterline RL, Vaag A, Oscarsson J \& Vora J. Mechanisms in endocrinology: SGLT2 inhibitors: clinical benefits by restoration of normal diurnal metabolism? European Journal of Endocrinology 2018178 R113-R125. (https://doi.org/10.1530/EJE-17-0832)

32 Kampmann U, Hoeyem P, Mengel A, Schmitz O, Rungby J, Orskov L \& Møller N. Insulin dose-response studies in severely insulinresistant type 2 diabetes - evidence for effectiveness of very high insulin doses. Diabetes, Obesity and Metabolism 201113 511-516. (https://doi.org/10.1111/j.1463-1326.2011.01373.x)

Received in final form 14 May 2020

Accepted 4 June 2020

Accepted Manuscript published online 4 June 2020

https://ec.bioscientifica.com https://doi.org/10.1530/EC-20-0082 (c) 2020 The authors Published by Bioscientifica Ltd

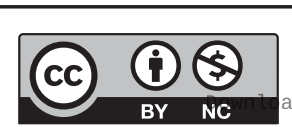

This work is licensed under a Creative Commons Attribution-NonCommercial 4.0 International License. ded from Bioscientifica.com at 04/26/2023 09:32:21AM 